\title{
Neuroprotection induced by Navß2-knockdown in APP/PS1 transgenic neurons is associated with NEP regulation
}

\author{
TAO HU ${ }^{1,2^{*}}$, SHAN-SHAN LI ${ }^{3 *}$, MIN-NAN LU ${ }^{4 *}$, LI ZHANG $^{5 *}$, BO CHEN $^{4 *}$, RUI MAO $^{6 *}$, \\ RONG MEI ${ }^{7}$, YA-XIN TAN ${ }^{1}$, SHAN LI ${ }^{1}$ and YAN-BIN XIYANG ${ }^{1}$
}

Institute of Neuroscience, Basic Medical College, Kunming Medical University, Kunming, Yunnan 650500;
${ }^{2}$ Department of Laboratory Medicine, The Third People's Hospital of Yunnan Province, Kunming, Yunnan 650011;
${ }^{3}$ Basic Medical College, ${ }^{4}$ Experiment Center for Medical Science Research, ${ }^{5}$ Editorial Department of Journal of
Kunming Medical University; ${ }^{6}$ School of Stomatology, Kunming Medical University, Kunming, Yunnan 650500;
${ }^{7}$ Department of Neurology, The First People's Hospital of Yunnan Province, Kunming, Yunnan 650032, P.R. China

Received November 1, 2018; Accepted May 29, 2019

DOI: $10.3892 / \mathrm{mmr} .2019 .10406$

\begin{abstract}
Voltage-gated sodium channel $\beta 2(\operatorname{Nav} \beta 2)$, as an unconventional substrate of $\beta$-site amyloid precursor protein cleaving enzyme 1 , is involved in regulating the neuronal surface expression of sodium channels. A previous study demonstrated that knockdown of Nav $\beta 2$ protected neurons and induced spatial cognition improvement by partially reducing pathological amyloidogenic processing of amyloid precursor protein (APP) in aged APP/presenilin 1 (PS1) transgenic mice. The present study aimed to investigate whether Nav $\beta 2$ knockdown altered APP metabolism via regulation of the $A \beta$-degrading enzyme neprilysin (NEP). APPswe/PS1 $\triangle \mathrm{E} 9$ mice (APP/PS1 transgenic mice with a C57BL/6J genetic background) carrying a Nav $\beta 2$-knockdown mutation (APP/PS1/Nav $\beta 2-k d)$ or without Nav $\beta 2$ knockdown (APP/PS1) were used for cell culture and further analysis. The present results demonstrated that in APP/PS1 mouse-derived neurons, Nav $\beta 2$ knockdown partially reversed the reduction in pathological APP cleavage, and the recovery of neurite extension and neuron area. Additionally, Nav $\beta 2$ knockdown increased NEP activity and levels, and the levels of intracellular domain fragment binding to the NEP promoter. The present findings suggested that knockdown of Nav $\beta 2$ reversed the APP/PS1 mutation-induced deficiency in amyloid $\beta$ degradation by regulating NEP.
\end{abstract}

Correspondence to: Dr Yan-Bin Xiyang, Institute of Neuroscience, Basic Medical College, Kunming Medical University, 1168 West Chunrong Road, Yuhua Avenue, Chenggong, Kunming, Yunnan 650500, P.R. China

E-mail: xiyang_neuro@126.com

${ }^{*}$ Contributed equally

Key words: voltage-gated sodium channel $\beta 2$, amyloid precursor protein/presenilin 1 mutation, Alzheimer's disease, amyloid precursor protein, neprilysin

\section{Introduction}

As the leading cause of dementia among the elderly, Alzheimer's disease (AD) usually induces cognitive deficits in patients, who require full-time care, burdening their families and health care systems (1). Therefore, developing viable anti-AD therapies is urgently required. As currently approved treatments only partially alleviate specific symptoms as opposed to effectively treating the complete AD pathology (2), improved understanding of the pathogenesis of $\mathrm{AD}$ is required for the development of more effective and potentially curative treatments.

It is well documented that the accumulation and aggregation of neurotoxic amyloid $\beta(\mathrm{A} \beta)$ peptides is a principal pathological feature of the AD brain that is proposed to be involved in the emergence of clinical manifestations in patients with $\mathrm{AD}$ (3). $\mathrm{A} \beta$ is generated from its precursor amyloid precursor protein (APP) by sequential cleavage (4). According to the amyloid hypothesis, the disequilibrium between $A \beta$ production and $A \beta$ degradation leads to $A \beta$ accumulation, and contributes to the primary neuropathogenesis of $\mathrm{AD}$ (5). In the amyloidogenic pathway, APP is first hydrolyzed by $\beta$-site APP-cleaving enzyme 1 (BACE1) to produce soluble (s)APP $\beta$ and $\beta$-C-terminal fragment ( $\beta$-CTF). The $\beta$-CTF is sequentially cleaved by $\gamma$-secretase to release $A \beta$ and the intracellular domain fragment (AICD) $(4,5)$. Accumulated $A \beta$ aggregates to generate $A \beta$ oligomers and amyloid plaques, potentially leading to the dysfunction of synapses and neuronal injury (6-8). Therefore, inhibition of $A \beta$ production and/or peptide oligomerization is considered a promising potential therapeutic strategy for AD (8). Additionally, there have been increasing efforts to identify disease-associated biomarkers of $\mathrm{AD}$ for diagnosis at early stages (9-11). This may aid the development of more effective and potentially curative treatments.

Voltage-gated sodium channel $\beta 2[\mathrm{Nav} \beta 2$ or Nav2.2, encoded by the sodium voltage-gated channel $\beta$ subunit 2 (SCN2B) gene], a voltage-gated sodium channel (VGSC) auxiliary subunit, is extensively distributed in the central nervous and cardiac systems (12). Generally, Nav $\beta 2$ regulates the activation 
and inactivation of Nav1.1 and Nav1.6 in a voltage-dependent manner $(12,13)$. The upregulation and diffuse distribution of Nav $\beta 2$ along demyelinated axons induces conduction block recovery and clinical remission $(14,15)$. As neuronal channel cell surface expression is regulated by $\operatorname{Nav} \beta 2$, Nav $\beta 2$ has also been demonstrated to be involved in the pathogenic processes underlying multiple sclerosis and experimental acute encephalitis (EAE) (16). It was reported that $N a v \beta 2$ regulates the cell surface expression of Nav1, which modulates propagation of the action potential and neuronal activity (17-19). Previous studies have also identified potential roles for Nav $\beta 2$ in APP cleavage and AD pathology. Nav $\beta 2$ was identified as a novel substrate of BACE1 and $\gamma$-secretase in model systems both in vivo and in vivo $(20,21)$. Nav 32 cleaved by BACE1 induced a leftward shift in the remodeling current of Nav1.2 (22). In a model of AD, BACE1 upregulation was associated with increased cleavage of Nav $\beta 2$ cleavage, upregulated expression of Nav1.1 in cortical neurons and abnormal EEG activity $(19,23)$.

A previous study demonstrated that increased $S C N 2 B$ expression in the hippocampus was associated with cognitive deficits in senescence-accelerated P8 mice (24). It was also reported that $\operatorname{Nav} \beta 2$ knockdown $(\mathrm{Nav} \beta 2-\mathrm{kd})$ protected neurons and improved spatial cognition in aged APP/presenilin 1 (APP/PS1) transgenic (Tg) mice by partially decreasing pathological amyloidogenic processing of APP (25). These results suggested that knockdown of $\mathrm{Nav} \beta 2$ may be a promising therapeutic strategy for AD; however, the underlying mechanisms remain unclear. The present study investigated whether Nav $\beta 2$ knockdown-induced neuroprotection and inhibition of APP amyloidogenic processing were associated with the activity and/or expressional regulation of the $A \beta$-degrading enzyme neprilysin (NEP).

\section{Materials and methods}

Ethics approval. All experimental procedures and animal care was in compliance with the Guide for the Care and Use of Laboratory Animals published by the US National Institutes of Health (26). The present study was performed in accordance with the Care and Use Guidelines of Experimental Animals established by the Research Ethics Committee of Kunming University of China that approved the study (permit no. kmu-eac-2017008). Surgical procedures were performed under anesthesia induced with diethyl ether. The purchase, storage and use of diethyl ether were approved by the associated departments and Kunming Medical University (license no. kmykdx-D-A00258). All efforts were made to minimize animal suffering during the experiments.

Animal model. In the present study, 16 APPswe/PS1 1 E9 (APP/PS1 transgene with a C57BL/6J genetic background; weight, $20-25 \mathrm{~g}$; age, 3-4 months; female to male ratio, 1:1) mice and the 16 wild type (WT) littermates were purchased from the Institute of Laboratory Animal Science (Chinese Academy of Medical Sciences). Nav $\beta 2-\mathrm{kd}(60.68 \%$ SCN2B transcription reduction) and APP/PS1/Nav $\beta 2-\mathrm{kd}$ Tg mice were generated and bred at Kunming Medical University as previously described $(24,25)$. Animals were maintained under standard conditions at $22^{\circ} \mathrm{C}$ with $55-60 \%$ humidity and a 12-h light/dark cycle. They were housed with free access to food and water. Mouse genomic DNA extracted from tail tissues was prepared for PCR, which was employed to screen the potential Tg founders. The presence of bands with target molecular weights was identified by PCR for the detection of positive transgenes as previously described [608 bp for APP/PS1 transgene; 453 bp for Nav $\beta 2-k d$ transgene; 608 and $453 \mathrm{bp}$ for APP/PS1/Nav $\beta 2-\mathrm{kd}$ transgene; and $350 \mathrm{bp}$ for wild-type (WT)] (25).

Cell preparation. Mice were anesthetized via inhalation of diethyl ether (2-3\% volume fraction; Shanghai Wulian Chemical Reagent Procurement and Supply Chemical Work) for 3-4 min. Anesthesia was induced using an animal inhalation anesthesia machine (AM Easy-Flex Auto Flow system; United Well Technologies Ltd.). The hippocampi were extracted from APP/PS1, Nav $32-k d$, APP/PS1/Nav $32-k d$, and WT mice following fast craniotomy, then the animals were sacrificed by dislocation of the cervical vertebrae. All efforts were made to minimize animal suffering during all surgical procedures, and the protocols were approved (permit no. kmu-eac-2017008). Primary hippocampus cell culture from the WT, APP/PS1/Nav $\beta 2-k d$, APP/PS1 and Nav $\beta 2-k d$ mice was conducted as previously described (25). Primary cells were resuspended by pipetting for $\geq 10$ times in $1 \mathrm{ml}$ Neurobasal medium (Invitrogen; Thermo Fisher Scientific, Inc.) supplemented with B27 (2\%; Gibco; Thermo Fisher Scientific, Inc.), N2 (1\%; Gibco; Thermo Fisher Scientific, Inc.), penicillin/streptomycin (100 U; Gibco; Thermo Fisher Scientific, Inc.) and L-glutamine ( $2 \mathrm{mM}$; Gibco; Thermo Fisher Scientific, Inc.) at $37^{\circ} \mathrm{C}$. In total, $1 \times 10^{6}$ neurons were seeded on six-well plates and incubated at $37^{\circ} \mathrm{C}$ with $5 \% \mathrm{CO}_{2}$. The medium was changed every 2 days until use. Using LEICA DMI6000B (LAS AF system; Leica Microsystems GmbH), morphological analysis was performed to evaluate the neuroprotection induced by Nav $\beta 2-\mathrm{kd}$. The axon lengths and areas of neurons were measured (magnification, $\mathrm{x} 200$ ).

To evaluate the effects of Nav $\beta 2-k d$ on the amyloidogenic processing of APP, cell culture medium was collected from the different groups for the detection of $\operatorname{APP} \alpha, \operatorname{sPP} \beta, A \beta 40$ and $\mathrm{A} \beta 42$ expression levels, whereas cell lysates were prepared to measure Nav $\beta 2$ and NEP expression, total $A \beta$ degradation detection, and to perform chromatin immunoprecipitation (ChIP) assays.

Reverse transcription-quantitative PCR (RT-qPCR). Cells were prepared for the detection of the gene expression levels of Nav $\beta 2$ and NEP by RT-qPCR as previously described $(27,28)$. TRIzol $^{\circledR}$ reagent (Invitrogen; Thermo Fisher Scientific, Inc.) was used to isolate total RNA from cultured cells. A RevertAid First Strand cDNA Synthesis kit (Fermentas; Thermo Fisher Scientific, Inc.) was used for RT of RNA. The first-strand cDNA was synthesized from $2 \mu \mathrm{g}$ total RNA that was quantified using a NanoDrop spectrophotometer (NanoDrop 1000; Thermo Fisher Scientific, Inc.). In total, $2 \mu \mathrm{g}$ total RNA was incubated with $1 \mu \mathrm{l}$ oligo (dT), $18 \mu \mathrm{l}$ random hexamers primers and $10 \mu \mathrm{l}$ diethyl pyrocarbonate-treated water at $70^{\circ} \mathrm{C}$ for $5 \mathrm{~min}$. The reaction was then incubated on ice for $10 \mathrm{sec}$. This mixture was subsequently supplied with $4 \mu 15 \mathrm{X}$ reaction buffer, $1 \mu$ l Riboblock ${ }^{\mathrm{TM}}$ Ribonuclease inhibitor and $10 \mathrm{mM}$ dNTP (all reagents were included in the kit), and incubated 
at $37^{\circ} \mathrm{C}$ for $5 \mathrm{~min}$. For cDNA synthesis, $1 \mu 1$ Revert Aid Moloney murine leukemia virus transcriptase was added to this mixture for an incubation at $42^{\circ} \mathrm{C}$ for $1 \mathrm{~h}$, followed by termination at $70^{\circ} \mathrm{C}$ for $10 \mathrm{~min}$. Fast SYBR Green Master Mix (Roche Diagnostics) was used for qPCR, and the results were analyzed using a Real-Time PCR System (Thermo Fisher Scientific, Inc.). qPCR was performed in $20 \mu \mathrm{l}$ reaction volume, including $2 X$ SYBR Green Master Mix (Roche Diagnostics) $10 \mu \mathrm{l}$, primer $(0.25 \mu \mathrm{l} ; 10 \mathrm{pmol} / \mathrm{l})$, template DNA $(1 \mu \mathrm{l})$ and sterile water $(8.5 \mu \mathrm{l})$. Then, qPCR amplification was performed at $95^{\circ} \mathrm{C}$ for $3 \mathrm{~min}$, followed by 34 thermocycling steps of $94^{\circ} \mathrm{C}$ for $35 \mathrm{sec}, 56.5^{\circ} \mathrm{C}$ for $30 \mathrm{sec}$ and at $72^{\circ} \mathrm{C}$ for $30 \mathrm{sec}$. To analyze the differences between samples, the relative $\mathrm{Cq}$ method was used. Following normalization to the housekeeping gene ( $\beta$-actin), fold changes (decrease or increase) were determined relative to a blank control using the $2^{-\Delta \Delta \mathrm{Cq}}$ method (29). Each reaction was repeated for three times. The following primer sequences were used (Takara Biotechnology Co., Ltd.): $\beta$-actin, forward 5'-TGGCACCCA GCACAATGAA-3', reverse 5'-CTAAGTCATAGTCCGCCT AGAAGCA-3' (30); Nav $\beta 2$, forward 5'-CTACACCGTGAA CCACAAGCA-3', reverse 5'-GACCACAGCCAGGAAACC C-3' (24); and NEP, forward 5'-TGAACTTTGCCCAGGTGT G-3', and reverse 5'-GCAAAGTCCCAATGATCCTG-3' (28).

Detection of APP cleavage production. The expression levels of A $\beta$, sAPP $\alpha$ and sAPP $\beta$ were detected to evaluate the effects of Nav $\beta 2-k d$ on APP amyloidogenic processing. Following 5 days of culturing, medium was obtained from the cell cultures of WT, APP/PS1, Nav $\beta 2-k d$ and APP/PS1/Nav $\beta 2-k d$ mice. Amyloid $\beta$ ELISA kits (Demeditec Diagnostics GmbH) were used to evaluate $A \beta 40$ (cat. no. JP27718) and A $\beta 42$ (cat. no. JP27719) expression levels, according to the manufacturer's protocol. The expression levels of $A \beta 40 / 42$ in cell culture media were compared between the different genotypes.

To determine sAPP $\alpha$ and sAPP $\beta$ expression levels, a sAPP $\alpha / \mathrm{sAPP} \beta$ multiplex electrochemiluminescence assay kit (cat. no. K15120E; 96-well MULTI-SPOT sAPP $\alpha /$ sAPP $\beta$ Assay; Meso Scale Discovery) was used. Cells were cultured in serum-free medium for $16 \mathrm{~h}$ at $37^{\circ} \mathrm{C}$ prior to harvesting. The cell medium was obtained to quantify sAPP $\alpha$ and sAPP $\beta$ expression levels, according to the manufacturer's protocol. Briefly, $150 \mu 1 /$ well of $3 \%$ Blocker A solution (included in the kit) was added in the plate and incubated at room temperature with shaking for $1 \mathrm{~h}$. The plate was washed with $300 \mu \mathrm{l} /$ well of $1 \mathrm{X}$ Tris buffer for three times. The $25 \mu \mathrm{l} /$ well of cell medium were added in the plate and incubated at room temperature for $1 \mathrm{~h}$, followed by washing for three times with $300 \mu \mathrm{l} /$ well of $1 \mathrm{X}$ Tris buffer. Then, $25 \mu \mathrm{l} /$ well of sAPP $\alpha$ or sAPP $\beta$ Calibrator (included in the kit) were added and incubated for $1 \mathrm{~h}$ at room temperature with shaking. The plate was washed again with $300 \mu \mathrm{l} /$ well $1 \mathrm{X}$ Tris buffer for three times. In total, $150 \mu \mathrm{l} /$ well 1X Read Buffer T (included in the kit) was then added and incubated for $10 \mathrm{~min}$ at room temperature without shaking. The plate was analyzed with a SECTOR Imager 2400 (Meso Scale Discovery).

Detection of protein expression. Samples from cultured cells were collected to evaluate Nav $\beta 2$ and NEP expression as previously described (25). Lysis buffer (10 mM Tris- $\mathrm{HCl}$ buffer pH 7.4, 10 mM EDTA, 30\% Triton-100, 10\% SDS and $150 \mathrm{mM} \mathrm{NaCl}$ ) supplemented with protease inhibitor cocktails (Roche Diagnostics $\mathrm{GmbH}$ ) was used to lyse cells. A total of $50 \mu \mathrm{g}$ protein (quantified using the bicinchoninic acid method) was used for SDS-PAGE on 4-12\% gels, followed by transfer to nitrocellulose membranes (Sigma-Aldrich; Merck KGaA). The membrane was subsequently incubated with antibodies specific for Nav $\beta 2$ (1:500; cat. no. ASC-007; Alomone Labs) or NEP (1:800; cat. no. ab951; Abcam) at $4^{\circ} \mathrm{C}$ for $12 \mathrm{~h}$. $\beta$-actin (mouse monoclonal anti- $\beta$-actin; $1: 800$; cat. no. sc-69879; Santa Cruz Biotechnology, Inc.) was used as the loading control. The membranes were washed and incubated with the peroxidase-conjugated anti-mouse secondary antibody (1:10,000; cat. no. PI-2000; Vector Laboratories, Inc.) or the horseradish peroxidase-conjugated anti-rabbit antibody (1:2,000; cat. no. PI-1000; Vector Laboratories, Inc.) at $20-25^{\circ} \mathrm{C}$ for $2 \mathrm{~h}$. Enhanced chemiluminescence reagent (Pierce; Thermo Fisher Scientific, Inc.) was used to visualize the bands. Densitometric analysis of the target protein bands was performed using a ChemiDoc ${ }^{\mathrm{TM}} \mathrm{RS}+$ imaging system and Image Lab ${ }^{\mathrm{TM}}$ software v5.2.1 (Bio-Rad, Laboratories, Inc.).

NEP activity evaluation. According to Grimm et al (28), the activity of NEP was evaluated. Briefly, $1 \times 10^{6}$ cells were treated with $500 \mu 1$ lysis buffer, containing $0.5 \%$ Triton X-100, $20 \mathrm{mM}$ Tris (pH 7.4) and $10 \%$ Sucrose at $4^{\circ} \mathrm{C}$ for $25 \mathrm{~min}$. A total of $2 \mu \mathrm{l}$ anti-NEP antibody (1:500; cat. no. AF1182; R\&D Systems, Inc.) and $5 \mu \mathrm{M}$ MCA-RPPGFSAFK(DNP)-OH fluorogenic peptide substrate (R\&D Systems, Inc.) were dissolved in HEPES buffer (pH 7.4) (Invitrogen; Thermo Fisher Scientific, Inc.). Cell lysates were incubated with anti-NEP antibody and fluorogenic substrate mixture ( $\mathrm{pH}$ 7.4) for $30 \mathrm{~min}$ at room temperature. Using a iMark Fluorometer Microplate Reader (Bio-Rad, Laboratories, Inc.), the fluorescence was evaluated with an excitation wavelength of $320 \pm 10 \mathrm{~nm}$ and an emission wavelength of $405 \pm 10 \mathrm{~nm}$.

Cell viability assay. The effects of Nav $\beta 2$-knockdown on the viability of primary cultured neurons were evaluated by measuring lactate dehydrogenase (LDH) activity using a Cytotoxicity Detection Kitplus (cat. no. 04744926001; Roche Diagnostics) according to the manufacturer's protocols.

A $\beta$ degradation detection. Total $\mathrm{A} \beta$ degradation was determined as previously described (28) with adjustments to the protocol. Lysis buffer $(150 \mathrm{mM} \mathrm{NaCl}, 50 \mathrm{mM}$ Tris/ $\mathrm{HCl} \mathrm{pH} \mathrm{7.4,}$ $2 \mathrm{mM}$ EDTA, $0.1 \%$ NP-40 and $0.1 \%$ Triton-X 100) was used to lyse cells at $20-25^{\circ} \mathrm{C}$ for $15 \mathrm{~min}$. In total, $60 \mu \mathrm{g}$ protein from each sample was incubated with $1 \mu \mathrm{g} / \mathrm{ml}$ synthetic human $\mathrm{A} \beta 40$ peptide (cat.no. A9810; Sigma-Aldrich; Merck KGaA) in $100 \mu 1$ PBS for $1 \mathrm{~h}$ at $37^{\circ} \mathrm{C}$. Additionally, $50 \mu \mathrm{M}$ thiorphan was added into the samples to determine the specificity of NEP-mediated $A \beta$ degradation. Quantification of the remaining $A \beta$ was performed using an anti- $\beta$-amyloid 40/42 (A $\beta 40 / 42)$ polyclonal antibody (1:800; cat. no. AB5076; EMD Millipore). The degrading activity in the lysates was evaluated and presented as the reciprocal value of the remaining quantified $\mathrm{A} \beta$ peptides. The Alexa Fluor 350-labeled secondary antibody anti-rabbit IgG (1:500; cat. no. A0408; Beyotime Institute of Biotechnology, Shanghai, China) was incubated at $37^{\circ} \mathrm{C}$ for 
$1.5 \mathrm{~h}$. The signals were analyzed using the SECTOR Imager 2400 (Meso Scale Discovery) (28).

ChIP analysis. ChIP was performed as previously described to determine the AICD enrichment of the promotor of the NEP gene (31-33). Briefly, Cells $\left(20 \times 10^{6}\right)$ were harvested with trypsin treatment and washed three times with PBS and then treated with $1 \%$ formaldehyde (Sigma-Aldrich) in PBS for 8-10 min at $4^{\circ} \mathrm{C}$. Fixation was stopped by addition of glycine to a final concentration of $125 \mathrm{mM}$. Extracts were sonicated at $20 \mathrm{kHz}$ for $2 \mathrm{~min}$ at room temperature repeated three times, and incubated with protein-G-Sepharose (GE Healthcare) for $1 \mathrm{~h}$ with rotation at room temperature, following treatment overnight at $4^{\circ} \mathrm{C}$ with anti-AICD (Y188; $1 \mu \mathrm{g}$; cat. no. ab32136; Abcam) or mouse immunoglobulin $\mathrm{G}$ (IgG; $1 \mu \mathrm{g}$; cat. no. ab18413; Abcam) primary antibody. Subsequently de-crosslinking and DNA isolation was performed prior to qPCR analysis. The PCR results were presented as the fold enrichment of DNA pulled down with the anti-AICD antibody compared with the IgG negative control.

Statistical analysis. The results are presented as the mean \pm standard deviation of the means of triplicate measurements of five independent experiments. One-way ANOVA followed by Fisher's least significant difference test were employed to analyze data using SPSS 11.5 (SPSS, Inc.). $\mathrm{P}<0.05$ was considered to indicate a statistically significant difference.

\section{Results}

Detection of $N a v \beta 2$ expression in cultured cells. Nav $\beta 2$ expression in cultured cells isolated from the different mice was evaluated by RT-qPCR and western blot analyses. Consistent with previous findings (25), Nav $\beta 2$ knockdown decreased the expression levels of the Nav $\beta 2$ gene (Fig. 1A) and protein (Fig. 1B) by $\sim 61 \%$ compared with the WT.

Expression and activity of NEP in cell culture. Compared with the WT group, NEP expression was significantly decreased in cultured cells derived from APP/PS1 mice; NEP gene expression levels decreased by $32.7 \pm 4.3 \%$, whereas NEP protein expression levels decreased by $35 \pm 5.1 \%$ (Fig. 2A and C). Nav $\beta 2$ knockdown induced a partial restoration of the expression of NEP in the APP/PS1/Nav/2-kd group. There was no significant difference between the WT and Nav $\beta 2-k d$ groups (P>0.05; Fig. 2).

Consistent with the NEP expression analysis, NEP activity was reduced to $74.5 \pm 3.9 \%$ in the APP/PS1 group, and recovered to $89 \pm 2.8 \%$ in APP/PS1/Nav $\beta 2-k d$ cells compared with the WT. Nav $\beta 2$ knockdown induced no effects on NEP activity compared with WT cells ( $\mathrm{P}>0.05$; Fig. 2B).

Measurement of cell viability. No difference in cell viability was detected in cells from APP/PS1 mice compared with WT mice, as determined by an LDH assay ( $\mathrm{P}>0.05$; Fig. 3 ). Additionally, compared with the WT group, Nav $\beta 2$-kd cells exhibited no significant difference in viability $(\mathrm{P}>0.05)$. Furthermore, there was no significant difference in the viability of cells obtained from the APP/PS1/Nav $\beta 2-k d$ mice, and those from APP/PS1 or Nav $\beta 2-k d$ mice.
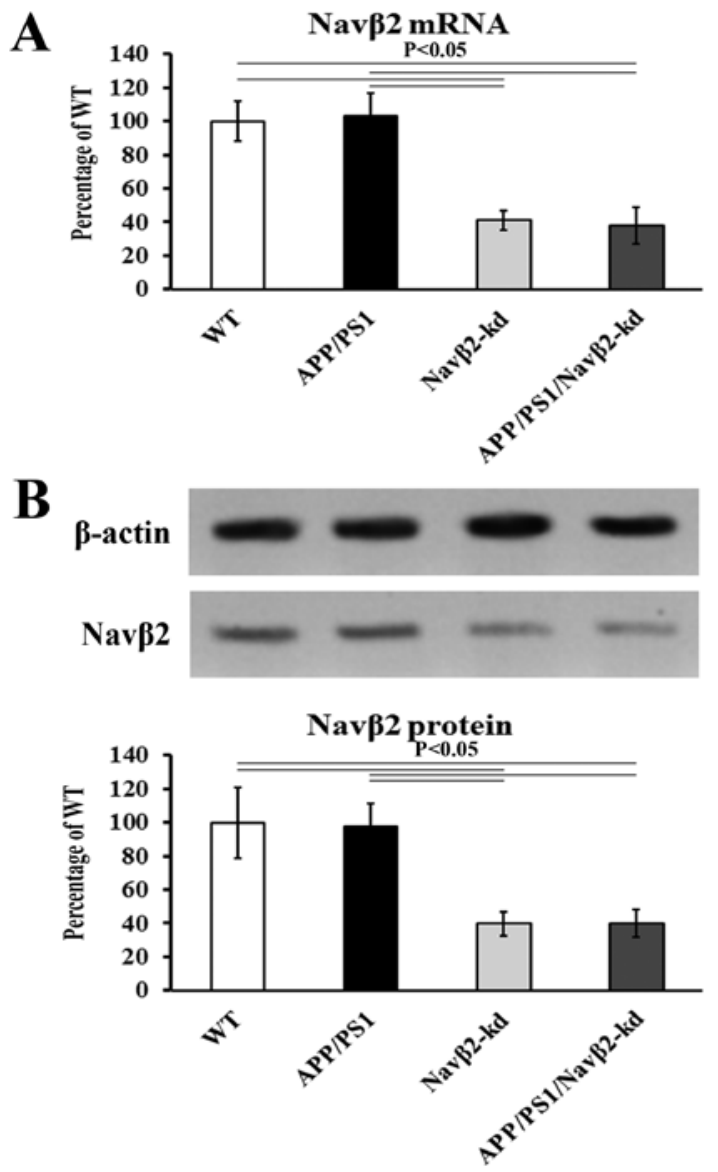

Figure 1. Nav $\beta 2$ expression in neurons. (A) mRNA levels of Nav $\beta 2$ evaluated by reverse transcription-quantitative PCR analysis in APP/PS1/Nav $\beta 2-k d$ $(0.25 \pm 0.08), \mathrm{Nav} \beta 2-\mathrm{kd}(0.27 \pm 0.06), \mathrm{APP} / \mathrm{PS} 1(0.67 \pm 0.14)$ and WT $(0.65 \pm 0.12)$ mouse-derived cells. (B) Protein levels of Nav $\beta 2$ evaluated by western blotting in APP/PS1/Nav $\beta 2-k d(0.16 \pm 0.08)$, Nav $\beta 2-k d(0.18 \pm 0.07)$, APP/PS1 (0.45 \pm 0.13$)$ and WT $(0.46 \pm 0.09)$ mouse-derived cells, respectively. Nav $\beta 2$, voltage-gated sodium channel $\beta 2$; APP, amyloid precursor protein; PS1, presenilin 1; kd, knockdown; WT, wild-type.

Evaluation of APP processing and $A \beta$ degradation. To evaluate the role of $\operatorname{Nav} \beta 2$ expressional knockdown in the amyloidogenic processing of APP, the levels of A $\beta$, sAPP $\alpha$ and sAPP $\beta$, and total A $\beta$ degradation were measured. Significant increases in $\mathrm{A} \beta 40$ and $\mathrm{A} \beta 42$ levels, and the ratio of $\mathrm{A} \beta 42 / \mathrm{A} \beta 40$ were observed in cultured cells derived from APP/PS1 mice compared with the WT group $(\mathrm{P}<0.05$; Fig. $4 \mathrm{~A}$ and $\mathrm{B})$. In the $\mathrm{APP} / \mathrm{PS} 1 / \mathrm{Nav} \beta 2-\mathrm{kd}$ group, the expression levels of $\mathrm{A} \beta 40$ and $\mathrm{A} \beta 42$, and the ratio of $\mathrm{A} \beta 42 / \mathrm{A} \beta 40$ were partially decreased compared with the APP/PS1 group. Additionally, reduced sAPP $\alpha$ and increased sAPP $\beta$ expression levels as determined via ECLIA were detected in cells derived from APP/PS1 mice, compared with the WT or Nav $\beta 2-k d$ groups $(\mathrm{P}<0.05$; Fig. $4 \mathrm{C}$ and D). The APP/PS1/Nav $32-k d$ transgene induced significant sAPP $\alpha$ upregulation, sAPP $\beta$ downregulation and an increased sAPP $\alpha / \mathrm{sAPP} \beta$ ratio in mouse cells compared with the APP/PS1 group ( $\mathrm{P}<0.05$; Fig. $4 \mathrm{C}$ and $\mathrm{D})$. Conversely, Nav $\beta 2$ knockdown alone induced no significant effects on A $\beta 40 / 42$, sAPP $\alpha$ or sAPP $\beta$ expression levels compared with the WT group $(\mathrm{P}<0.05$; Fig. 4$)$.

Total degradation of endogenous $A \beta$ was measured in the cell lysates of the different groups. Total degradation of 
A

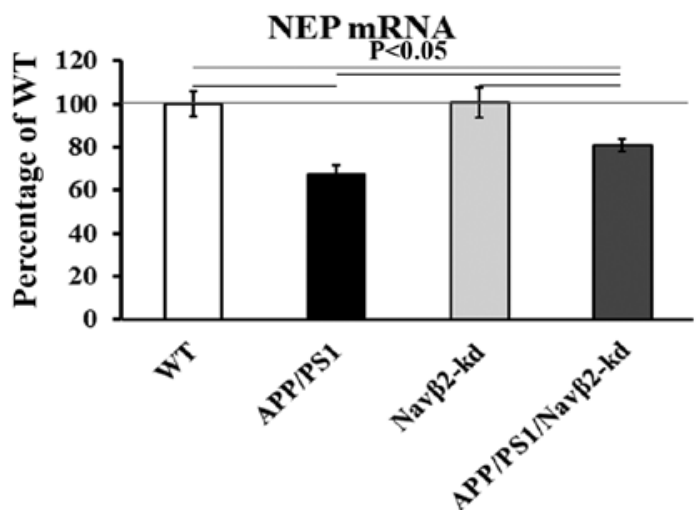

B

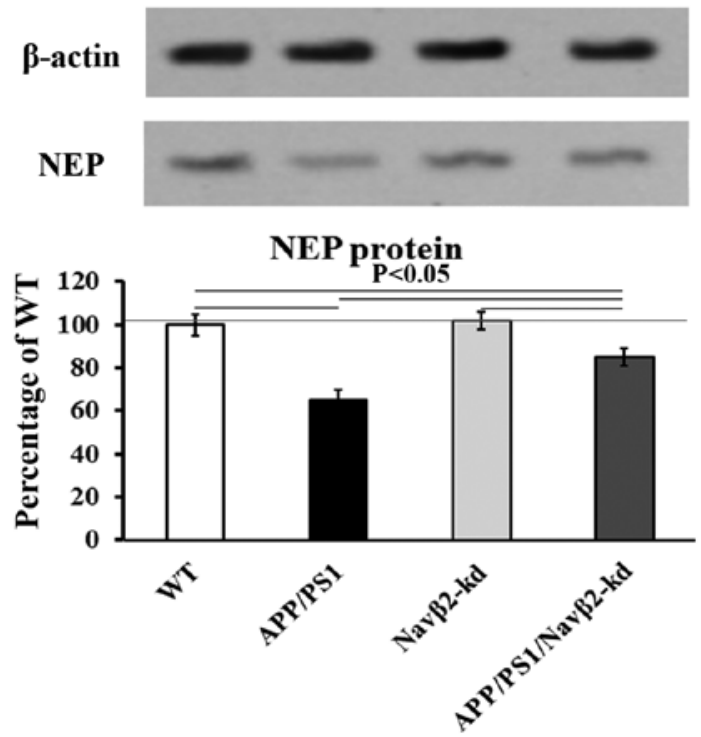

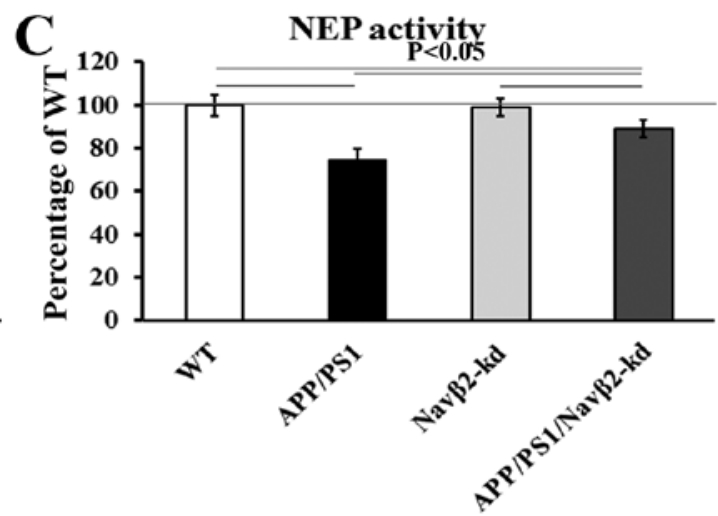

Figure 2. Effects of Nav $\beta 2$ knockdown on the expression and activity of NEP. (A) mRNA levels of NEP as determined via reverse transcription-quantitative PCR analysis in APP/PS1/Nav $\beta 2-k d, N a v \beta 2-k d$, APP/PS1 and WT mouse-derived neurons. (B) Activity of NEP in cells derived from APP/PS1/Nav $\beta 2-k d$, Nav $\beta 2-k d$, APP/PS1 and WT mice. (C) Protein levels of NEP as determined via western blotting in APP/PS1/Nav $\beta 2-k d$, Nav $\beta 2-k d$, APP/PS1 and WT mouse-derived cells. Nav $\beta 2$, voltage-gated sodium channel $\beta 2$; APP, amyloid precursor protein; PS1, presenilin 1; kd, knockdown; WT, wild-type; NEP, neprilysin.

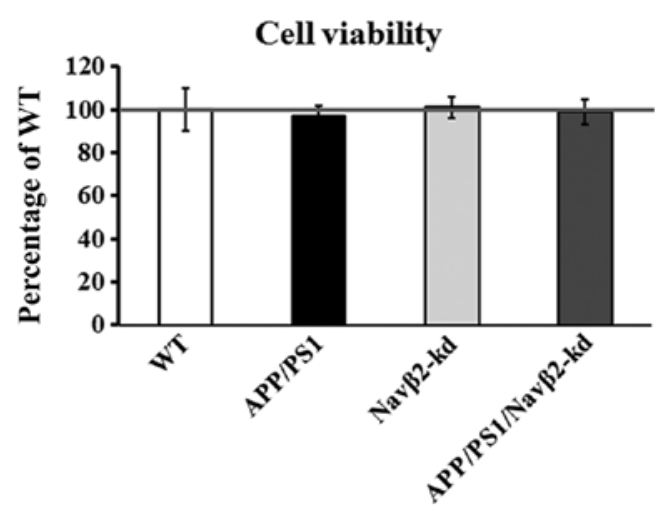

Figure 3. Effects of Nav $\beta 2$ knockdown on cell viability. A lactate dehydrogenase assay was performed to evaluate the viability of APP/PS1/Nav $\beta 2-\mathrm{kd}$, Nav $\beta 2-k d$, APP/PS1 and WT mouse-derived neurons. There were no significant different detected between the various groups. Nav $\beta 2$, voltage-gated sodium channel $\beta 2$; APP, amyloid precursor protein; PS1, presenilin 1; kd, knockdown; WT, wild-type.

A $\beta$ 40/42 in the lysates of APP/PS1 cells significantly decreased to $53.1 \pm 6.4 \%$ compared with the WT (Fig. 4E). Nav $\beta 2$ knockdown induced a partial recovery of $A \beta$ degradation in the
APP/PS1/Nav 32 -kd group compared with the APP/PS1 group, without reaching the levels of the WT group. There was no significant difference between WT and Nav $\beta 2-k d$ cells.

Nav $\beta 2$ knockdown enhances the enrichment of AICD in the NEP promoter in cells with APP/PS1. ChIP analysis demonstrated that the APP/PS1 transgene significantly decreased the enrichment of AICD in the NEP promoter compared with WT or Nav $\beta 2$-kd cells, $(\mathrm{P}<0.05$; Fig. 5). Nav $\beta 2$ knockdown significantly increased AICD binding to the promoter of the NEP gene in APP/PS1/Nav $\beta 2$-kd cells compared with the APP/PS1 group $(\mathrm{P}<0.05$; Fig. 5); however, it did not restore AICD enrichment to WT levels ( $\mathrm{P}<0.05$ vs. WT; Fig. 5). No statistical difference was detected between WT- and Nav $\beta 2$-kd-derived cells ( $\mathrm{P}>0.05$; Fig. 5).

Nav $\beta 2-k d$ promotes neurite outgrowth in APP/PS1 cells. The APP/PS1 transgene induced a significant decrease in the neurite extension $(\mathrm{P}<0.05)$ and areas $(\mathrm{P}<0.05)$ of cultured cells compared with the WT group (Fig. 6). Nav $\beta 2-k n o c k d o w n$ rescued the reduced neurite outgrowth in APP/PS1/Nav $\beta 2-k d$ cells $(\mathrm{P}<0.05$; Fig. 6); however, Nav $\beta 2$ knockdown alone 
A

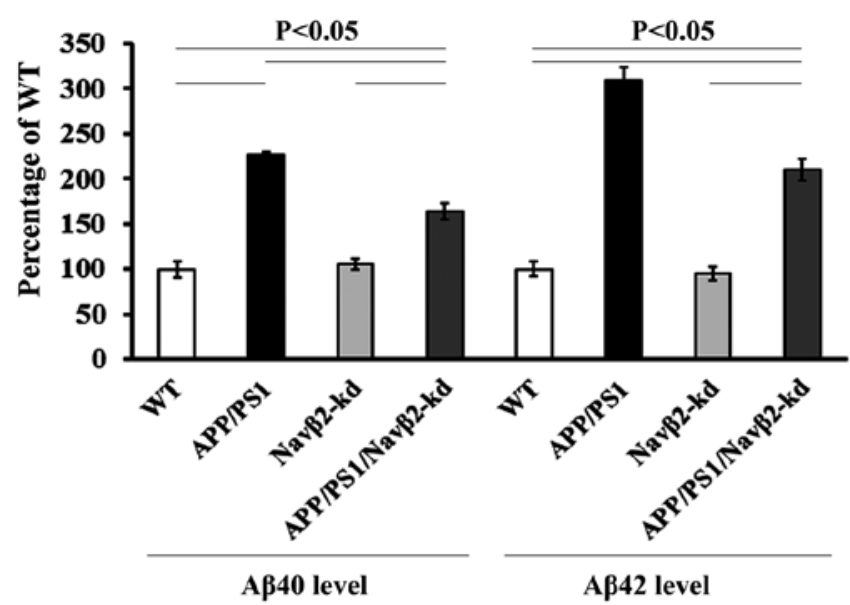

B
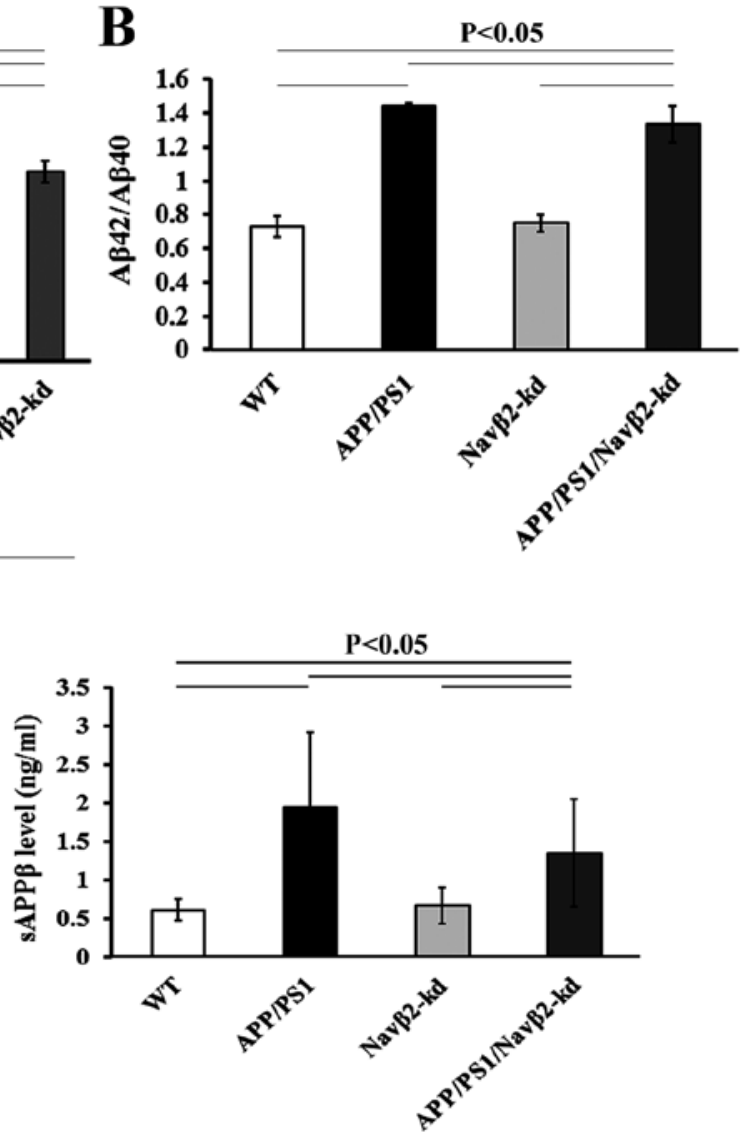

$\mathbf{E}$

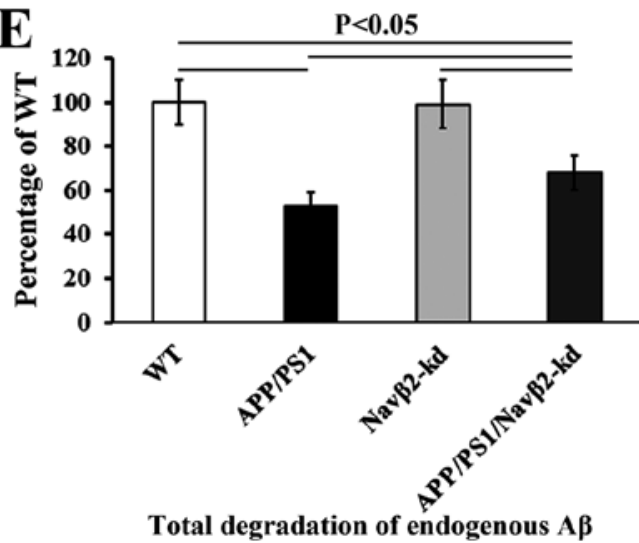

Figure 4. Nav $\beta 2$ knockdown affects APP processing and A $\beta$ degradation. (A) A $\beta 40 / 42$ levels, (B) A $\beta 42 / A \beta 40$ ratio, (C) sAPP $\alpha$ and sAPP $\beta$ levels, (D) sAPP $\alpha / \mathrm{sAPP} \beta$ ratio and (E) total A $\beta$ degradation in lysates of APP/PS1/Nav $\beta 2-k d$, Nav $\beta 2-k d$, APP/PS1 and WT mouse-derived neurons. Nav $\beta 2$, voltage-gated sodium channel $\beta 2$; APP, amyloid precursor protein; PS1, presenilin 1; kd, knockdown; WT, wild-type; s, soluble.

induced no effects on the extension or the area of cells compared with the WT $(\mathrm{P}>0.05)$.

\section{Discussion}

Knockdown of Nav $\beta 2$ expression in APP/PS1 mice has been reported to convert the amyloidogenic processing of APP induced by APP/PS1 mutation toward non-amyloidogenic metabolism (25); however, the underlying mechanisms remain unclear. The present study investigated whether Nav $\beta 2$ knockdown altered APP amyloidogenic metabolism via the regulation of NEP. The data demonstrated that Nav $\beta 2$ knockdown induced a partial recovery of NEP expression and activity, an increased level of AICD binding to the promoter of NEP gene, and decreased $A \beta$ generation in APP/PS1 mutant mice. Additionally, Nav $\beta 2$ knockdown promoted neurite extension and increased the neuronal area in cultured cells derived from APP/PS1-mutated mice. These data suggested that expressional knockdown of Nav $\beta 2$ partially rectified the APP/PS1 mutation induced-amyloid clearance deficit, and attenuated the effects on neurites and neuron area induced by APP/PS1 mutation via regulation of the expression and activity of NEP.

Primary hippocampal neurons derived from APP/PS1 $\mathrm{Tg}$ mouse were used in the present study; these cells are frequently used to investigate the pathological conditions 


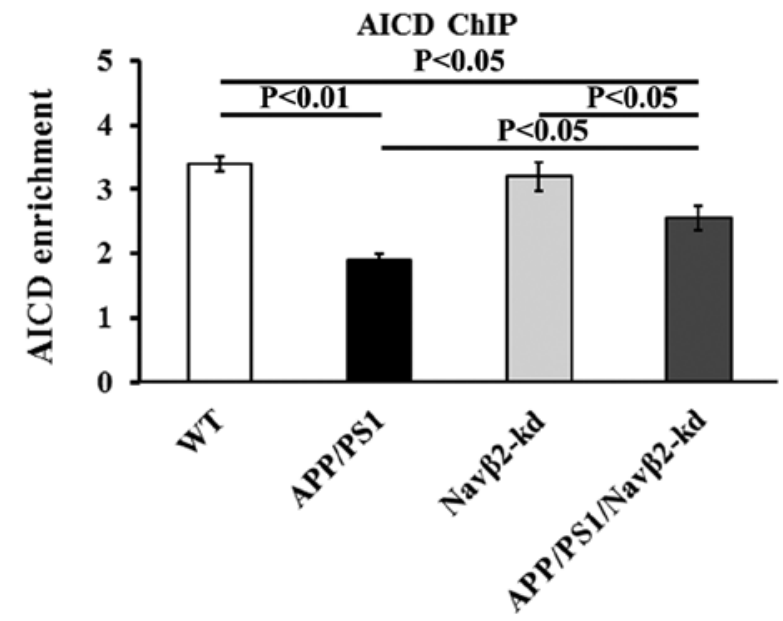

Figure 5. Nav $\beta 2$ knockdown increases the levels of AICD binding to the NEP promotor. Effects of Nav $\beta 2$ knockdown on AICD enrichment of the NEP gene promoter in APP/PS1/Nav $\beta 2-k d, N a v \beta 2-k d$, APP/PS1 and WT mouse-derived neurons, as determined by a ChIP assay. AICD enrichment is presented as the fold enrichment compared with that obtained with non-specific immunoglobulin G. Nav $\beta 2$, voltage-gated sodium channel $\beta 2$; APP, amyloid precursor protein; PS1, presenilin 1; kd, knockdown WT, wild-type; NEP, neprilysin; ChIP, chromatin immunoprecipitation; AICD, APP intracellular domain.
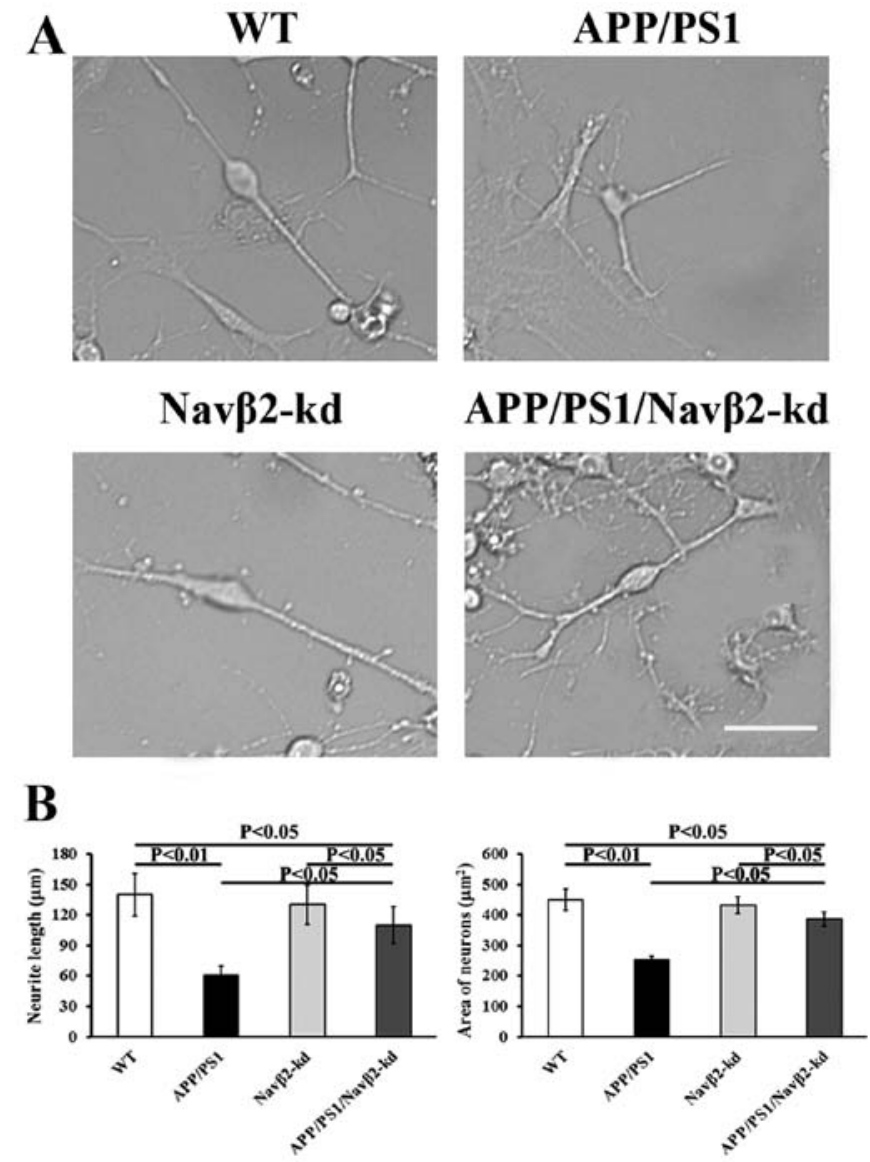

Figure 6. Effects of $\operatorname{Nav} \beta 2$ knockdown on morphological changes in APP/PS1 mutant neurons. (A) Micrograph of cultured cells derived from APP/PS1/Nav $\beta 2-k d, N a v \beta 2-k d, A P P / P S 1$ and WT mice Magnification, x200. Scale bar, $100 \mu \mathrm{m}$. (B) Quantitation of the neurite length and area of APP/PS1/Nav/32-kd, Nav $\beta 2-\mathrm{kd}$, APP/PS1 and WT mouse-derived neurons. Nav $\beta 2$, voltage-gated sodium channel $\beta 2$; APP, amyloid precursor protein; PS1, presenilin 1; kd, knockdown; WT, wild-type. and mechanisms of AD (34). It was suggested that the Swedish mutation of APP (APPswe) may be processed by the $\beta$-secretase-mediated amyloidogenic pathway instead of $\alpha$-secretase-dependent non-amyloidogenic processing; the double mutation of APPswe at the crucial cleavage site targeted by $\beta$-secretase is proposed to result in an increase in $\mathrm{A} \beta$ production $(35,36)$.

The present findings revealed that increased $A \beta 40,-42$, and sAPP $\beta$ expression levels, and decreased sAPP $\alpha$ levels were detected in APP/PS1 mutant cells. Additionally, the ratio of sAPP $\alpha /$ APP $\beta$ decreased, and A $\beta$ degradation was reduced. In cells derived from APP/PS1/Nav $\beta 2-k d$ mice, Nav $\beta 2$ knockdown induced enhanced $A \beta$ degradation, decreased A $\beta 40 / 42$ and sAPP $\beta$ production, and increased the expression levels of $\operatorname{sAPP} \alpha$ and the ratio of sAPP $\alpha / \mathrm{sAPP} \beta$. During $\alpha$-secretase processing, APP is cleaved and releases sAPP $\alpha$ into the extracellular space; the remaining 83 amino acids in the membrane are subsequently processed by $\gamma$-secretase to generate an $A \beta$ truncated fragment p3 (37,38). As indicated by ectodomain shedding, $\mathrm{APP} \alpha$ production is the initial procedure in non-amyloidogenic processing, whereas sAPP $\beta$ generation is the initial step in amyloidogenic processing (39). Increased cleavage of APP by $\alpha$-secretase resulted in decreased $\mathrm{A} \beta$ production (40). Consistent with a previous in vivo study, the present findings indicated that expressional knockdown of Nav 32 attenuated amyloidogenic metabolism of APP induced by APP/PS1 mutation in favor of non-amyloidogenic processing in vitro (25).

It was previously demonstrated that brain $A \beta$ expression levels represent a dynamic balance between APP-derived A $\beta$ production and elimination by a series of amyloid clearance proteins (6-8). At present, the group of known enzymes capable of A $\beta$ degradation comprises $>20$ members $(41,42)$, including the NEP family (NEP and NEP2), endothelin-converting enzyme-1 and -2 , and insulin-degrading enzyme (41-43). A $\beta$ may be metabolized by these enzymes, producing metabolites with reduced neurotoxicity (44). NEP, a member of the neutral zinc metalloendopeptidase family, is a plasma membrane glycoprotein of 90-110 kDa $(45,46)$. The decline in expression levels and activity of NEP leads to a clearance deficit of amyloid, which is considered as a principal pathogenic factor in sporadic AD $(47,48)$. Therefore, recovery of NEP expression and activity may be a promising therapeutic approach for $\mathrm{AD}$.

A constitutive regulatory processing (49) and an epigenetically-regulated component $(32,50)$ are responsible for the complexity of NEP expressional regulation. Among them, the epigenetically-regulated component involves an unstable transcription factor, AICD, which is derived from $\beta$-secretase amyloidogenic processing of APP. AICD is a competitive binding component to the NEP gene promoter (51). By binding to the promoter of NEP, AICD induces activation of NEP transcription, leading to increased NEP activity and A $\beta$ clearance; histone deacetylases inhibit this process $(52,53)$.

In the present study, it was observed that APP/PS1/Nav $\beta 2-k d$ neurons exhibited reduced $A \beta 40 / 42$ generation and increased total $A \beta$ degradation compared with the APP/PS1 mutation group. To determine whether Nav $\beta 2$ knockdown enhanced $\mathrm{A} \beta$ degradation via NEP regulation, the levels and activity of NEP in APP/PS1 mutant neurons with or without Nav $\beta 2$ 
knockdown were evaluated. AICD enrichment in the promoter region of NEP was detected by a ChIP assay. As hypothesized, the data demonstrated that Nav $\beta 2$ knockdown induced increased expression and activity levels of NEP, and increased AICD binding to the NEP gene, which suggested that Nav $\beta 2$ knockdown rectified the APP/PS1 mutation induced-amyloid clearance deficit in a NEP-dependent manner. Considering that Nav $\beta 2$ is a substrate of BACE1, which is a key APP-cleaving enzyme for APP hydrolyzation via the amyloidogenic pathway, it is hypothesized that $\operatorname{Nav} \beta 2$ knockdown may alter the activity of BACE1 and thus interfere with the amyloidogenic pathway of APP, leading to reduced A $\beta$ production. Li et al (54) identified that APP modulated Nav1.6 sodium channels via a $\mathrm{G}_{\mathrm{o}}$-coupled JNK-mediated pathway, which is dependent on phosphorylation of APP at Thr668. Nav $\beta 2$ causes activation and inactivation of Nav1.1 and Nav1.6 in a voltage-dependent manner. O'Malley et al (16) demonstrated that Nav $\beta 2$ knockout attenuated the upregulation of Nav1.6 protein expression in the brain of an animal model of EAE (16). Therefore, it is additionally proposed that Nav $\beta 2$ knockdown may interact with APP associated with Nav1.6 and influence APP processing; however, further studies are required to verify these hypotheses.

Additionally, Nav $\beta 2$ knockdown induced no effects on cellular LDH activity; however, it prolonged neurite extension in APP/PS1/Nav $\beta 2-k d \mathrm{Tg}$ neurons. It is hypothesized that Nav $\beta 2$, as an associated auxiliary subunits of VGSCs, which modulate channel activity, may serve roles in regulating neuronal activity via interactions with Nav1.1/1.6, stabilizing the sodium current density and maintaining channel expression on the cell surface of neurons as opposed to altering the cell viability $(12,13,17)$.

A previous in vivo study reported that knockdown of $\mathrm{Nav} \beta 2$ in APP/PS1 mice induced partial restoration of neuronal activity of hippocampal neurons and improvement of spatial cognitive function (25). The present in vitro data demonstrated that Nav $\beta 2$ knockdown induced neurite extension and restoration of the neuronal area, which may be associated with the recovery of neuroplasticity and contribute to cognitive improvement in APP/PS1 mice.

Additionally, this previous study reported decreased levels of Nav $\beta 2$ CTF and a reversal of abnormal Nav $\beta 2$ cleavage by BACE1 and $\gamma$-secretase following Nav $\beta 2$ knockdown in a APP/PS1 transgene model of AD (25). Upregulation of the $\mathrm{Nav} \beta 2$ gene in the brains of aged SAMP8 mice was previously observed (24). MicroRNAs (miRNAs/miRs) are small noncoding RNAs that bind via base pair interactions with the 3'-untranslated region of target mRNAs to either degrade the mRNA or repress its translation (55). Aberrant miRNA expression may contribute to the progression of neurodegenerative diseases $(56,57)$. A previous study additionally identified different expressional profiles of miRNAs between the brains of SAMP8 mice and SAMR1 control mice. It was demonstrated that miR-9 and miR-9* serve important roles during aging via interactions with target genes in SAMP8 mice; one of the target genes of miR-9 is $S C N 2 B$, a Nav 32 -coded gene (58). Therefore, it is hypothesized that hydrolysis status and/or miR levels may make important contributions to the regulation of the Nav $\beta 2$ gene; however, further investigation is required to verify this hypothesis.
In conclusion, the present findings demonstrated that Nav $\beta 2$ knockdown in cultured APP/PS1-derived neurons induced a partial recovery of NEP expression and activity, an increase in AICD enrichment of the NEP promoter, a decrease in $A \beta$ generation, and restoration of neurite length and area. These findings suggested that $\operatorname{Nav} \beta 2$ knockdown partially recovered the deficiency of $\mathrm{A} \beta$ cleavage and retarded neurite outgrowth induced by the APP/PS1 mutation, by protecting the expression and activity of NEP, and enhancing the levels of ACID binding to the NEP gene.

\section{Acknowledgements}

Not applicable.

\section{Funding}

This research was supported by the National Natural Science Foundation of China (grant nos. 81560238, 81502377 and 81701212), Yunnan Applied Basic Research Foundation of Yunnan Province in China (grant nos. 2016FB139 and 2016FB123), Special Fund of the Applied Basic Research Programs of Yunnan Province associated with Kunming Medical University in China (grant no. 2015FB001), Foundation of Science and Technology Innovative Team Building of Kunming Medical University (grant no. CXTD201807), and the Medical Reserve Talents Cultivation Project of the Health and Family Planning Commission of Yunnan Province (grant no. H-2017026).

\section{Availability of data and materials}

The datasets used and analyzed in the present study are available from the corresponding author on reasonable request.

\section{Authors' contributions}

TH and YBX made substantial contributions towards the design and conception of the present study. YBX and SSL drafted and critically revised the manuscript. LZ, SSL, MNL, $\mathrm{RMa}$, SL and BC performed cell and animal model preparation. LZ, MNL, RMa, YXT, SSL, RMe, SL and TH performed RT-qPCR, APP cleavage detection and western blot analyses. LZ, MNL, YXT, SSL and YBX performed the NEP activity evaluation. TH, SSL, MNL, BC, RMa and YBX performed NEP activity evaluation and the cell viability assay. LZ and YBX conducted the ChIP analysis. All authors have read and approved the final manuscript.

\section{Ethics approval and consent to participate}

All experiments and care of animal were in compliance with the Guide for the Care and Use of Laboratory Animals published by the US National Institutes of Health. This study was conducted in accordance with the Care and Use Guidelines of Experimental Animals established by the Research Ethics Committee of Kunming University of China, who approved the present study (permit no. kmu-eac-2017008). The purchase, storage and use of the diethyl ether in the present study were approved by the associated departments and Kunming Medical University (license no. kmykdx-D-A00258). 


\section{Patient consent for publication}

Not applicable.

\section{Competing interests}

The authors declare that they have no competing interests.

\section{References}

1. Jia J, Wei C, Chen S, Li F, Tang Y, Qin W, Zhao L, Jin H, Xu H, Wang $\mathrm{F}$, et al: The cost of Alzheimer's disease in China and re-estimation of costs worldwide. Alzheimers Dement 14 483-491, 2018

2. Yiannopoulou KG and Papageorgiou SG: Current and future treatments for Alzheimer's disease. Ther Adv Neurol Disord 6 : 19-33, 2013.

3. Chu J,Li JG, Hoffman NE, Madesh M and Praticò D: Degradation of gamma secretase activating protein by the ubiquitin-proteasome pathway. J Neurochem 133: 432-439, 2015.

4. Esler WP and Wolfe MS: A portrait of Alzheimer secretases-new features and familiar faces. Science 293: 1449-1454, 2001.

5. Glenner GG and Wong CW: Alzheimer's disease: Initial report of the purification and characterization of a novel cerebrovascular amyloid protein. Biochem Biophys Res Commun 120: 885-890, 1984.

6. Agostinho P, Pliássova A, Oliveira $\mathrm{CR}$ and Cunha RA: Localization and trafficking of amyloid- $\beta$ protein precursor and secretases: Impact on Alzheimer's disease. J Alzheimers Dis 45: 329-347, 2015.

7. Ashe KH and Zahs KR: Probing the biology of Alzheimer's disease in mice. Neuron 66: 631-645, 2010.

8. Sakono $\mathrm{M}$ and Zako T: Amyloid oligomers: Formation and toxicity of Abeta oligomers. FEBS J 277: 1348-1358, 2010.

9. Liu LJ, Leung KH, Chan DS, Wang YT, Ma DL and Leung CH: Identification of a natural product-like STAT3 dimerization inhibitor by structure-based virtual screening. Cell Death Dis 5: e1293, 2014.

10. Ito M, Tanaka T, Toita A, Uchiyama N, Kokubo H, Morishita N, Klein MG, Zou H, Murakami M, Kondo M, et al: Discovery of 3-Benzyl-1-(trans-4-((5-cyanopyridin-2-yl)amino) cyclohexyl)-1-arylurea derivatives as novel and selective cyclindependent kinase 12 (CDK12) inhibitors. J Med Chem 61: $7710-7728,2018$.

11. Ma DL, Lin S, Wang W, Yang C and Leung CH: Luminescent chemosensors by using cyclometalated iridium(iii) complexes and their applications. Chem Sci 8: 878-889, 2017.

12. Dhar Malhotra J, Chen C, Rivolta I, Abriel H, Malhotra R, Mattei LN, Brosius FC, Kass RS and Isom LL: Characterization of sodium channel alpha- and beta-subunits in rat and mouse cardiac myocytes. Circulation 103: 1303-1310, 2001.

13. Vijayaragavan K, Powell AJ, Kinghorn IJ and Chahine M: Role of auxiliary beta1-, beta2-, and beta3-subunits and their interaction with $\mathrm{Na}(\mathrm{v}) 1.8$ voltage-gated sodium channel. Biochem Biophys Res Commun 319: 531-540, 2004.

14. Bechtold DA and Smith KJ: Sodium-mediated axonal degeneration in inflammatory demyelinating disease. J Neurol Sci 233: 27-35, 2005.

15. Waxman SG: Axonal conduction and injury in multiple sclerosis: The role of sodium channels. Nat Rev Neurosci 7: 932-941, 2006.

16. O'Malley HA, Shreiner AB, Chen GH, Huffnagle GB and Isom LL: Loss of $\mathrm{Na}^{+}$channel beta2 subunits is neuroprotective in amouse model of multiple sclerosis. Mol Cell Neurosci 40 $143-155,2008$

17. Chen C, Bharucha V, Chen Y, Westenbroek RE, Brown A Malhotra JD, Jones D, Avery C, Gillespie PJ III, KazenGillespie KA, et al: Reduced sodium channel density, altered voltage dependence of inactivation, and increased susceptibility to seizures in mice lacking sodium channel beta 2-subunits. Proc Natl Acad Sci USA 99: 17072-17077, 2002.

18. Lopez-Santiago LF, Pertin M, Morisod X, Chen C, Hong S, Wiley J, Decosterd I and Isom LL: Sodium channel beta2 subunits regulate tetrodotoxin-sensitive sodium channels in small dorsal root ganglion neurons and modulate the response to pain. J Neurosci 26: 7984-7994, 2006.
19. Kim DY, Carey BW, Wang H, Ingano LA, Binshtok AM, Wertz MH, Pettingell WH, He P, Lee VM, Woolf CJ and Kovacs DM: BACE1 regulates voltage-gated sodium channels and neuronal activity. Nat Cell Biol 9: 755-764, 2007.

20. Wong HK, Sakurai T, Oyama F, Kaneko K, Wada K, Miyazaki H, Kurosawa M, De Strooper B, Saftig P and Nukina N: beta subunits of voltage-gated sodium channels are novel substrates of beta-site amyloid precursor protein-cleaving enzyme (BACE1) and gamma-secretase. Biol Chem 280: 23009-23017, 2005.

21. Kim DY, Ingano LA, Carey BW, Pettingell WH and Kovacs DM Presenilin/gamma-secretase-mediated cleavage of the voltage-gated sodium channel beta2-subunit regulates cell adhesion and migration. J Biol Chem 280: 23251-23261, 2005.

22. Huth T, Schmidt-Neuenfeldt K, Rittger A, Saftig P, Reiss K and Alzheimer C: Non-proteolytic effect of beta-site APP cleaving enzyme 1 (BACE1) on sodium channel function. Neurobiol Dis 33: $282-289,2009$.

23. Corbett BF, Leiser SC, Ling HP, Nagy R, Breysse N, Zhang X, Hazra A, Brown JT, Randall AD, Wood A, et al: Sodium channel cleavage is associated with aberrant neuronal activity and cognitive deficits in a mouse model of Alzheimer's disease. J Neurosci 33: 7020-7026, 2013.

24. XiYang YB, Wang YC, Zhao Y, Ru J, Lu BT, Zhang YN, Wang $\mathrm{NC}, \mathrm{Hu} \mathrm{WY}$, Liu J, Yang JW, et al: Sodium channel-voltage-gated-beta 2 plays a vital role in brain aging associated with synaptic plasticity and expression of COX5A and FGF-2. Mol Neurobiol 53: 955-967, 2016.

25. Hu T, Xiao Z, Mao R, Chen B, Lu MN, Tong J, Mei R, Li SS, Xiao ZC, Zhang LF and Xiyang YB: Nav $\beta 2$ knockdown improves cognition in APP/PS1 mice by partially inhibiting seizures and APP amyloid processing. Oncotarget 8: 99284-99295, 2017.

26. National Research Council (US) Committee for the Update of the Guide for the Care and Use of Laboratory Animals: Guide for the Care and Use of Laboratory Animals, 8th edition. National Academies Press, Washington, DC, 2011.

27. Hu T, Li YS, Chen B, Chang YF, Liu GC, Hong Y, Chen HL and Xiyang YB: Elevated glucose-6-phosphate dehydrogenase expression in the cervical cancer cases is associated with the cancerigenic event of high-risk human papillomaviruses. Exp Bio Med (Maywood) 240: 1287-1297, 2015.

28. Grimm MO, Mett J, Stahlmann CP, Grösgen S, Haupenthal VJ, Blümel T, Hundsdörfer B, Zimmer VC, Mylonas NT, Tanila H, et al: APP intracellular domain derived from amyloidogenic $\beta$ - and $\gamma$-secretase cleavage regulates neprilysin expression. Front Aging Neurosci 7: 77, 2015.

29. Livak KJ and Schmittgen TD: Analysis of relative gene expression data using real-time quantitative PCR and the 2(-Delta Delta $\mathrm{C}(\mathrm{T})$ ) method. Methods 25: 402-408, 2001

30. Hu T, Chang YF, Xiao Z, Mao R, Tong J, Chen B, Liu GC, Hong Y, Chen HL, Kong SY, et al: miR-1 inhibits progression of high-risk papillomavirus-associated human cervical cancer by targeting G6PD. Oncotarget 7: 86103-86116, 2016.

31. Zuccato C, Belyaev N, Conforti P, Ooi L, Tartari M, Papadimou E, MacDonald M, Fossale E, Zeitlin S, Buckley N and Cattaneo E: Wide spread disruption of repressor element-1 silencing transcription factor/neuron-restrictive silencer factor occupancy at its target genes in Huntington's disease. J Neurosci 27: 6972-6983, 2007.

32. Belyaev ND, Nalivaeva NN, Makova NZ and Turner AJ: Neprilysin gene expression requires binding of the amyloid precursor protein intracellular domain to its promoter: Implications for Alzheimer disease. EMBO Rep 10: 94-100, 2009.

33. Kerridge C, Kozlova DI, Nalivaeva NN and Turner AJ: Hypoxia affects neprilysin expression through caspase activation and an APP intracellular domain-dependent Mechanism. Front Neurosci 9: 426, 2015.

34. Mullan M, Crawford F, Axelman K, Houlden H, Lilius L, Winblad B and Lannfelt L: A pathogenic mutation for probable Alzheimer's disease in the APP gene at the N-terminus of beta-amyloid. Nat Genet 1: 345-347, 1992.

35. Citron M, Oltersdorf T, Haass C, McConlogue L, Hung AY, Seubert P, Vigo-Pelfrey C, Lieberburg I and Selkoe DJ: Mutation of the beta-amyloid precursor protein in familial Alzheimer's disease increases beta-protein production. Nature 360, 672-674, 1992.

36. Felsenstein KM, Hunihan LW and Roberts SB: Altered cleavage and secretion of a recombinant beta-APP bearing the Swedish familial Alzheimer's disease mutation. Nat Genet 6: 251-255, 1994. 
37. Esch FS, Keim PS, Beattie EC, Blacher RW, Culwell AR Oltersdorf T, McClure D and Ward PJ: Cleavage of amyloid beta peptide during constitutive processing of its precursor. Science 248: 1122-1124, 1990.

38. Lichtenthaler SF: $\alpha$-secretase in Alzheimer's disease: Molecular identity, regulation and therapeutic potential. J Neurochem 116: 10-21, 2011.

39. Hardy J and Selkoe DJ: The amyloid hypothesis of Alzheimer's disease: Progress and problems on the road to therapeutics. Science 297: 353-356, 2002.

40. Xie Z and Xu Z: General anesthetics and $\beta$-amyloid protein. Prog Neuropsychopharmacol Biol Psychiatry 47: 140-146, 2013.

41. Nalivaeva NN, Beckett C, Belyaev ND and Turner AJ: Are amyloid-degrading enzymes viable therapeutic targets in Alzheimer's disease? J Neurochem 120 (Suppl 1): S167-S185, 2012

42. Nalivaeva NN, Belyaev ND, Kerridge C and Turner AJ: Amyloidclearing proteins and their epigenetic regulation as a therapeutic target in Alzheimer's disease. Front Aging Neurosci 6: 235, 2014

43. Marr RA and Spencer BJ: NEP-like endopeptidases and Alzheimer's disease. Curr Alzheimer Res 7: 223-229, 2010.

44. Pacheco-Quinto J and Eckman EA: Endothelin-converting enzymes degrade intracellular $\beta$-amyloid produced within the endosomal/lysosomal pathway and autophagosomes. J Biol Chem 288: 5606-5615, 2013

45. Miners JS, Baig S, Palmer J, Palmer LE, Kehoe PG and Love S: Abeta-degrading enzymes in Alzheimer's disease. Brain Pathol 18: 240-252, 2008.

46. Turner AJ, Brown CD, Carson JA and Barnes K: The neprilysin family in health and disease. Adv Exp Med Biol 477: 229-240, 2000.

47. Turner AJ, Isaac RE and Coates D: The neprilysin (NEP) family of zinc metalloendopeptidases: Genomics and function. Bioessays 23: 261-269, 2001.

48. Selkoe DJ: Preventing Alzheimer's disease. Science 337: $1488-1492,2012$

49. Pluta R, Jabłoński M, Ułamek-Kozioł M, Kocki J, Brzozowska J, Januszewski S, Furmaga-Jabłońska W, Bogucka-Kocka A, Maciejewski R and Czuczwar SJ: Sporadic Alzheimer's disease begins as episodes of brain ischemia and ischemically dysregulated Alzheimer's disease genes. Mol Neurobiol 48: 500-515, 2013.
50. Li C, Booze RM and Hersh LB: Tissue-specific expression of rat neutral endopeptidase (neprilysin) mRNAs. J Biol Chem 270: 5723-5728, 1995.

51. Pardossi-Piquard R, Petit A, Kawarai T, Sunyach C, Alves da Costa C, Vincent B, Ring S, D'Adamio L, Shen J, Müller U, et al: Presenilin-dependent transcriptional control of the Abeta-degrading enzyme neprilysin by intracellular domains of betaAPP and APLP. Neuron 46: 541-554, 2005.

52. Belyaev ND, Kellett KA, Beckett C, Makova NZ, Revett TJ, Nalivaeva NN, Hooper NM and Turner AJ: The transcriptionally active amyloid precursor protein (APP) intracellular domain is preferentially produced from the 695 isoform of APP in a $\{$ beta $\}$-secretase-dependent pathway. J Biol Chem 285: 41443-41454, 2010.

53. Kerridge C, Belyaev ND, Nalivaeva NN and Turner AJ: The $\mathrm{A} \beta$-clearance protein transthyretin, like neprilysin, is epigenetically regulated by the amyloid precursor protein intracellular domain. J Neurochem 130: 419-431, 2014

54. Li S, Wang X, Ma QH, Yang WL, Zhang XG, Dawe GS and Xiao ZC: Amyloid precursor protein modulates Nav1.6 sodium channel currents through a Go-coupled JNK pathway. Sci Rep 6: 39320, 2016.

55. Hansen TB, Jensen TI, Clausen BH, Bramsen JB, Finsen B, Damgaard CK and Kjems J: Natural RNA circles function as efficient microRNA sponges. Nature 495: 384-388, 2013.

56. Hébert SS and De Strooper B: Alterations of the microRNA network cause neurodegenerative disease. Trends Neurosci 32: 199-206, 2009.

57. Lukiw WJ: Micro-RNA speciation in fetal, adult and Alzheimer's disease hippocampus. Neuroreport 18: 297-300, 2007.

58. Liu W, Liu C, Yin B and Peng XZ: Functions of miR-9 and miR-9* during aging in SAMP8 mice and their possible mechanisms. Zhongguo Yi Xue Ke Xue Yuan Xue Bao 37: 253-258, 2015. 